\title{
Studies on Neonatal Disorders Induced by Drugs
}

\author{
By \\ Tetuya Kitayama \\ From the Department of Obstetrics and Gynecology, Tohoku University \\ School of Medicine, Sendai; Director: Prof. K. Kushima
}

(Received for publication, August 5, 1964)

\begin{abstract}
Bilirubin dissolved in the solvent of an optimal composition was injected into the peritoneal cavity of newborn rats and excess bilirubin remaining in the liver was then determined. An excess bilirubin was given intraperitoneally to the newborn rats. 48 hours later, the animals were killed, and the liver was extracted with $80 \%$ acetone. The optimal composition of the solvent for crystalline bilirubin to be injected intraperitoneally was found to be $\mathrm{Na}_{2} \mathrm{CO}_{3} 1.05 \mathrm{~g} / \mathrm{dl}+$ $\mathrm{NaCl} 0.85 \mathrm{~g} / \mathrm{dl}$; and $0.125 \mathrm{mg}$ of bilirubin was found to be adequate for the newborn rat when inhibiting action of drugs on bilirubin conjugation and excretion was to be studied.
\end{abstract}

It has been well known that the newborn infants, particularly the premature, are apt to suffer from toxicosis due to various drugs. Some develop severe icterus resulting in cerebral disorders and toxic death. In our department also the cases were observed which had developed kernicterus due to administration of an excess amount of vitamin $\mathrm{K}_{4}$. It is because the newborn infants with a special functional state are medicated with the dosis calculated solely by their body weight, or because they are medicated excessively without understanding their immature pathophysiology.

It is, therefore, necessary to determine the optimal dosis of drugs for the newborn infants from the standpoint of their intoxication.

It is now widely recognized that physiological neonatal jaundice develops owing to insufficient enzymatic activity in the liver which results in insufficient conjugation of an excess bilirubin with glucuronides ${ }^{1-3)}$. There are still many points left to be clarified to explain why an excess amount of bilirubin is difficult to be loaded experimentally to newborn animals.

Bilirubin loading to the newborn rats was performed only by Waters and Britton $^{4)}$ to study its effect on kernicterus by injecting crystalline bilirubin. In their experiment, many rats died probably because hypersaturated carbonic acid solution was used as a solvent. Therefore, this method cannot be used for testing the conjugating and excreting activities of bilirubin. Thus, the author introduced

北山哲也 
a new method in which bilirubin dissolved in the solvent of an optimal salt composition was injected into the peritoneal cavity of newborn rats and then an excess bilirubin remaining in the liver was determined. It is the purpose of this paper to report on the method for studying neonatal toxicosis induced by drugs.

\section{MATERIALS AND METHODS}

Seven to 15 day-old rats of Wistar strain, weighing $10-14 \mathrm{~g}$ in body weight were used. For comparison, the rats from the same litter were separated into 2 groups, but no consideration was given to sex difference. Crystalline bilirubin used was the one commercially available from Daiichi Chemical Co., and HitachiEPB-U spectrophotometer was used.

\section{RESULTS}

1) Optimal concentration of $\mathrm{Na}_{2} \mathrm{CO}_{3}$

An excess amount of bilirubin was given to the newborn rats intraperitoneally. In the present experiments, the solvent of bilirubin was the most critical point to be previously studied.

The solvent to be used should dissolve bilirubin easily, be absorbed from the peritoneal cavity, and have the least toxicity for the newborn rats. Therefore, the optimal concentration of $\mathrm{Na}_{2} \mathrm{CO}_{3}$ was studied first by determining the toxicity on intravenous injection and by observing yellow crystalline remnants in the peritoneal cavity after it was given intraperitoneally. The volume injected was $0.1 \mathrm{ml}$.

a) Toxicity of $\mathrm{Na}_{2} \mathrm{CO}_{3}$ on the newborn rats

Toxicity of $\mathrm{Na}_{2} \mathrm{CO}_{3}$ was studied at the following three concentrations: the hypersaturated solution ( $\mathrm{pH} 8-9$, adjusted with $1 \mathrm{NHCl}$ ), which was used by Waters and Britton ${ }^{4)}$ on experimental kernicterus; $5 \mathrm{~g} / \mathrm{dl}$, which is used in adults for bilirubin loading test $\left.{ }^{5}\right) ; 1.05 \mathrm{~g} / \mathrm{dl}$, which was twice as large as the concentration used by Weinbren and Billing ${ }^{6)}$ for liver clearance test in adult rats, and equivalent to $0.1 \mathrm{M}$ concentration. The concentration of $1.05 \mathrm{~g} / \mathrm{dl}$ proved most suitable because the majority of the animals died with the other 2 concentrations used. Further, $0.85 \mathrm{~g} / \mathrm{dl}$ of $\mathrm{NaCl}$ was added in order to minimize the peritoneal irritation. The results are shown in Table I. Only 3 out of 24 rats died, similarly to that in the control group.

TABLE I. Death with Different Concentrations of $\mathrm{Na}_{2} \mathrm{CO}_{3}$

\begin{tabular}{l|c|c}
\hline Concentration & Nos. of cases & Nos. of death \\
\hline 1) $\mathrm{Na}_{2} \mathrm{CO}_{3} 47 \mathrm{~g} / \mathrm{dl}(\mathrm{pH} 8-9)$ & 11 & 10 \\
2) $\mathrm{Na}_{2} \mathrm{CO}_{3} 5 \mathrm{~g} / \mathrm{dl}$ & 12 & 12 \\
3) $\mathrm{Na}_{2} \mathrm{CO}_{3} 1.05 \mathrm{~g} / \mathrm{dl}+\mathrm{NaCl} 0.85 \mathrm{~g} / \mathrm{dl}$ & 24 & 3 \\
Control & 20 & 3
\end{tabular}


b) Intraperitoneal yellow crystalline remnants when an excess bilirubin is given Bilirubin was dissolved in the solvent $\left(\mathrm{Na}_{2} \mathrm{CO}_{3} \quad 1.05 \mathrm{~g} / \mathrm{dl}+\mathrm{NaCl} 0.85 \mathrm{~g} / \mathrm{dl}\right)$, and this bilirubin solution was diluted with the equal volume of the same solvent. Five days after the injection, the abdomen was opened, and yellow crystalline remnants in the peritoneal cavity and on the liver were measured. The results are shown in Table II: (H) indicates abundant precipitation, (H) moderate, $(+)$ slight, $( \pm)$ minimal, and $(-)$ none.

Table II. Yellow Crystalline Remnant in Peritoneal Cavity Five Days after the Injection

\begin{tabular}{|c|c|c|c|c|c|}
\hline \multirow[t]{2}{*}{$\begin{array}{l}\text { Bilirubin injected* } \\
\text { (volume } \mathrm{ml} \text { ) }\end{array}$} & \multicolumn{5}{|c|}{ Yellow orystalline remnant } \\
\hline & $(+\#)$ & $(H t)$ & $(+)$ & $( \pm)$ & $(\rightarrow)$ \\
\hline $\begin{array}{l}0.25 \mathrm{mg}(0.1) \\
0.25 \mathrm{mg}(0.1)+\mathrm{Na}_{2} \mathrm{CO}_{3}(0.1) \\
0.25 \mathrm{mg}(0.1)+\mathrm{NaCl}^{2}(0.1) \\
0.125 \mathrm{mg}(0.1)+\mathrm{Na}_{2} \mathrm{CO} \mathrm{O}_{3}(0.1) \\
0.125 \mathrm{mg}(0.1)+\mathrm{NaCl}(0.1) \\
0.125 \mathrm{mg}(0.1)\end{array}$ & $\begin{array}{l}1 \\
3 \\
1 \\
0 \\
0 \\
0\end{array}$ & $\begin{array}{l}4 \\
2 \\
4 \\
0 \\
0 \\
0\end{array}$ & $\begin{array}{l}1 \\
0 \\
1 \\
2 \\
2 \\
0\end{array}$ & $\begin{array}{l}1 \\
1 \\
0 \\
2 \\
3 \\
2\end{array}$ & $\begin{array}{l}0 \\
0 \\
1 \\
1 \\
1 \\
4\end{array}$ \\
\hline
\end{tabular}

Yellow crystalline remnants precipitated depend not only on the amount of bilirubin given, but also on the volume of the solvents used. When a small amount of bilirubin such as $0.125 \mathrm{mg}$ was given, almost no remnant was seen. With this amount, it was not necessary to add the $\mathrm{Na}_{2} \mathrm{CO}_{3}$ or $\mathrm{NaCl}$ before the injection.

2) Absorption curve of $80 \%$ acetone-extract of bilirubin loaded newborn rat liver

Ten $\mathrm{mg}$ of erystalline bilirubin was dissolved in $4 \mathrm{ml}$ of the solvent, and it was injected into the peritoneal cavity of the newborn rat. Immediately after killing the animal, the liver was removed and was washed once with $80 \%$ acetone. $200 \mathrm{mg}$ of the liver fragment were resected and was homogenized with $3 \mathrm{ml}$ of $80 \%$ acetone. After centrifugation, the supernatant fluid was measured spectrophotometrically with $520-380 \mathrm{~m} \mu$. A typical absorption curve of bilirubin in acetone extract of the liver loaded with bilirubin and those of the liver unloaded with bilirubin are shown in Fig. 1.

As Fig. 1 shows, the absorption curve for the liver loaded with bilirubin (the uppermost curve) reveals the superimposition of the curve of bilirubin in $80 \%$ acetone, having the peak at $460 \mathrm{~m} \mu$ on the curve for the liver not loaded with bilirubin. Since the absorption curve of bilirubin has the peak at $460 \mathrm{~m} \mu$, intrahepatic bilirubin can be measured by determining the optical density at $460 \mathrm{~m} \mu$. 


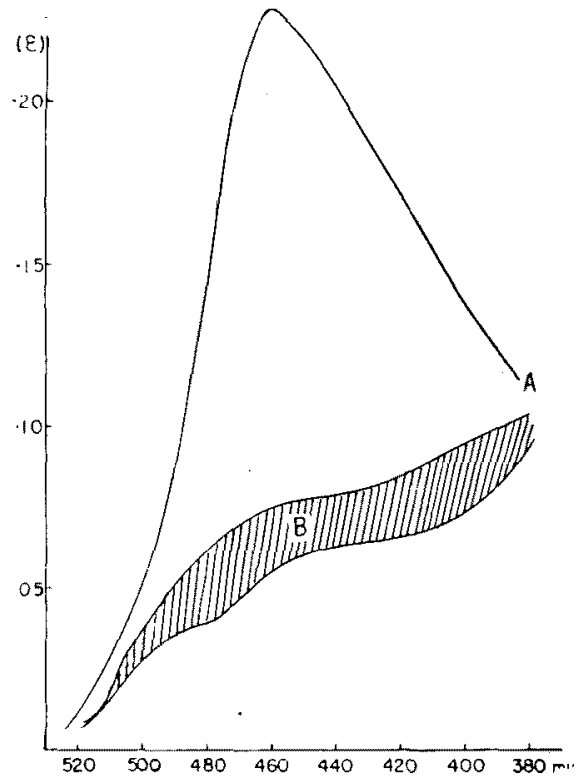

Fig. 1. A, the absorption curve of the acetone extract of the liver loaded with bilirubin; and $B$, the absorption curves of the acetone extract liver unloaded with bilirubin (control 6 cases).

When the optical density of the liver loaded with bilirubin is lower than the one of the liver not loaded with bilirubin, it may be considered that an excess bilirubin given is not remaining in the liver.

Theile and Dieckhoff? extracted indirect bilirubin from brain tissue with $80 \%$ acetone, and Mertz and West ${ }^{8}$ measured indirect bilirubin in the serum after protein and direct bilirubin were removed by adding $80 \%$ acetone. It was assumed that in the newborn rats, also, loaded bilirubin might be excreted as direct bilirubin. Thus, bilimubin extracted by $80 \%$ acetone was considered to be indirect bilirubin.

3) Amounts of bilirubin injected and time required for excretion

The amount of remaining bilirubin in the liver loaded with bilirubin was evaluated by measuring the optical density at $460 \mathrm{~m} \mu$, that in the liver unloaded with bilirubin serving as control.

a) $0.25 \mathrm{mg}$ of bilirubin was given to 7 day-old rats weighing $10-11 \mathrm{~g}$ and 15 day-old rats weighing $13-14.5 \mathrm{~g}$, and the bilirubin remained in the liver was measured periodically. The results are shown in Fig. 2. The optical density decreased gradually, but the values were still variable. The high values seen even after 5 days were probably due to the substance precipitated on the surface of the liver. 


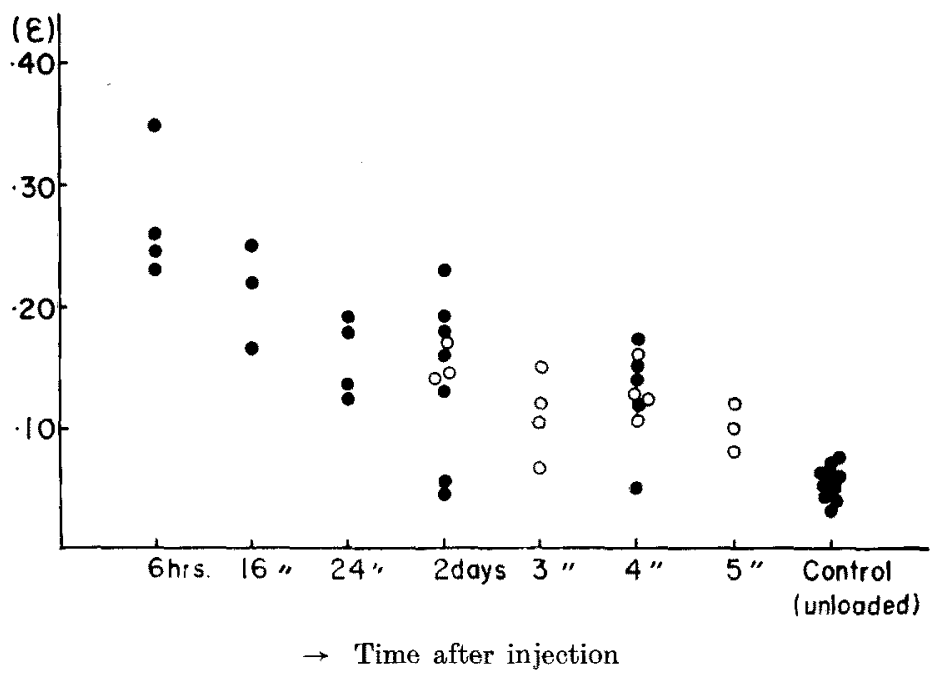

Fig. 2. The optical density of indirect bilirubin from the liver after loading with bilirubin in $0.25 \mathrm{mg}$.

Filled circles: 7-day-old rats. Empty circles: 15-day-old rats.

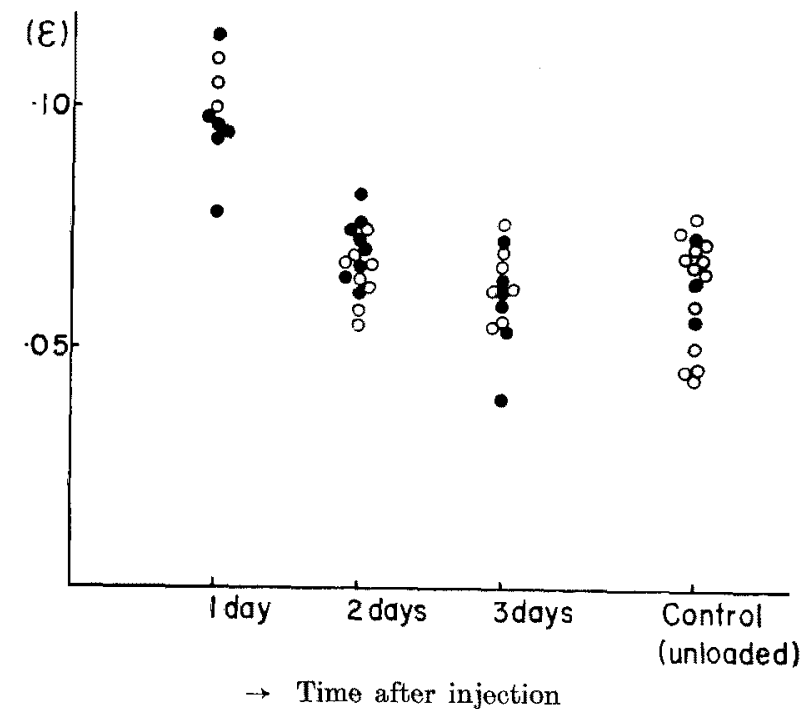

Fig. 3. The optical density of indirect bilirubin from the liver after loading with bilirubin in $0.125 \mathrm{mg}$.

Filled circles: 14-day-old rats. Empty circles: 10-day-old rats.

b) $0.125 \mathrm{mg}$ of bilirubin was given to 10 to 14 -day-old rats weighing $12-12.5$ $\mathrm{g}$, and the optical density was measured periodically. The results are shown in Fig. 3. Even 3 days after the injection, a small amount of the yellow substance 
was precipitated over the hepatic surface in some cases, but the most of the cases showed the optical density similar to that obtained with the extracts of the liver unloaded with bilirubin. Therefore, an excess bilirubin may be considered to have been excreted out.

\section{References}

1) Brown, A.K. \& Zuelzer, W.W., J. clin. invest., 1958, 37, 332.

2) Brown, A.K., Amer. J. Dis. Child., 1957, 94, 510.

3) Zuelzer, W.W., ibid., 1961, 101, 87.

4) Waters, W. J. \& Britton, H.A., Pediat., 1955, 15, 45.

5) Bergmann, G.V., Klin. Wschr., 1927, 6, 776.

6) Weinbren, K. \& Billing, B.H., Brit. J. exp. Path., 1956, 37, 199.

7) Theile, H. \& Dieckhoff, J., Zschr. Kinderh., 1961, 85, 141.

8) Mertz, J.E. \& West, C.D., Amer. J. Dis. Child., 1956, 91, 19. 